\title{
DNA vaccination with CD25 protects rats from adjuvant arthritis and induces an antiergotypic response
}

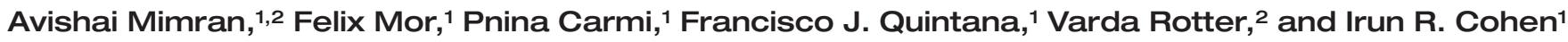 \\ 1Department of Immunology and 2Department of Molecular Cell Biology, The Weizmann Institute of Science, Rehovot, Israel.
}

\begin{abstract}
Ab's to the $\alpha$-chain of the IL-2 receptor (anti-CD25) are used clinically to achieve immunosuppression. Here we investigated the effects of DNA vaccination with the whole CD25 gene on the induction of rat adjuvant arthritis. The DNA vaccine protected the rats and led to a shift in the cytokine profile of T cells responding to disease target antigens from Th1 to Th2. The mechanism of protection was found to involve the induction of an antiergotypic response, rather than the induction of anti-CD25 Ab's. Antiergotypic T cells respond to activation molecules, ergotopes, expressed on syngeneic activated, but not resting, $\mathrm{T}$ cells. CD25-derived peptides function as ergotopes that can be recognized by the antiergotypic $T$ cells. Antiergotypic $T$ cells taken from control sick rats did not proliferate against activated $T$ cells and secreted mainly IFN- $\gamma$. In contrast, antiergotypic cells from CD25-DNA-protected rats proliferated against activated T cells and secreted mainly IL-10. Protective antiergotypic $\mathrm{T}$ cells were found in both the $\mathrm{CD4}^{+}$and $\mathrm{CD8}^{+}$populations and expressed $\alpha / \beta$ or $\gamma / \delta \mathrm{T}$ cell receptors. Antiergotypic $\alpha / \beta$ T cells were MHC restricted, while $\gamma / \delta$ T cells were MHC independent. Thus, CD25 DNA vaccination may induce protection from autoimmunity by inducing a cytokine shift in both the antiergotypic response and the response to the antigens targeted in the disease.
\end{abstract}

\section{Introduction}

Since the mid-1980s, Ab's to the $\alpha$-chain of the IL-2 receptor (CD25) have been used to achieve immunosuppression; the administration of specific mAb's to CD25 blocks the binding of IL-2 to its receptor and inhibits allograft rejection (1-7). Anti-CD25 administration has been proposed for treating T cell-dependent autoimmune diseases (5). Here we describe the use of vaccination with DNA encoding CD25 to inhibit an experimental autoimmune disease - adjuvant arthritis (AA).

CD25 is a marker for $T$ cell activation expressed on activated T cells but not on resting or memory $\mathrm{T}$ cells (8-10). Indeed, molecules expressed on activated $\mathrm{T}$ cells can serve as target antigens for the regulatory $\mathrm{T}$ cells called antiergotypic T cells. Antiergotypic T cells appear to recognize molecules that mark the activation state (ergotopes) of the target $\mathrm{T}$ cells they regulate (11). The antiergotypic response is not clonally restricted and can be targeted to activated $\mathrm{T}$ cells regardless of their idiotypic specificities. Antiergotypic T cells transferred to Lewis rats were found to protect them from the induction of experimental autoimmune encephalomyelitis (EAE) (11).

The ergotopes recognized by antiergotypic $T$ cells were found to be structural components of the activated $\mathrm{T}$ cell and not secreted factors $(11,12)$. Since the expression of CD25 is induced upon T cell activation, it was suggested that CD25 might serve as an ergotope (13). Indeed, rat $\mathrm{T}$ cell lines raised to immunogenic peptides of CD25 were found to proliferate in culture in the presence of activated syngeneic T cells (13).

Nonstandard abbreviations used: adjuvant arthritis (AA); $\alpha$-chain of the IL-2 receptor (IL-2R $\alpha$ ); $\gamma$-chain of the IL-2 receptor (IL-2R $\gamma$ ); concanavalin A (conA); draining lymph node (DLN); experimental autoimmune encephalomyelitis (EAE); heat shock protein 60 (HSP60); mean spontaneous proliferation (MSP); 2-mercaptoethanol (2-ME); Mycobacterium tuberculosis (Mt); myelin basic protein (MBP); purified protein derivative (PPD); resting A6 T cells (A6-R); stimulated A6 T cells (A6-S); stimulation index (SI); $\mathrm{T}$ cell growth factor (TCGF); $\mathrm{T}$ cell receptor (TCR); $\mathrm{T}$ regulatory $1(\mathrm{Tr} 1)$.

Conflict of interest: The authors have declared that no conflict of interest exists. Citation for this article: J. Clin. Invest. 113:924-932 (2004). doi:10.1172/JCI200417772.
Antiergotypic T cells seem to have clinical relevance. Trials of T cell vaccination in multiple sclerosis have used autologous, activated $\mathrm{T}$ cells responsive to myelin antigens (14-16). Vaccination with such $\mathrm{T}$ cells has led not only to anti-idiotypic $\mathrm{T}$ cell responses, but also to activation of antiergotypic T cells. Antiergotypic T cells have been described as one of the mechanisms by which $T$ cell vaccination might protect humans from autoimmunity $(17,18)$.

In this study we vaccinated rats with the whole CD25 gene and measured its effect on the induction of AA, a model for autoimmune arthritis (19). DNA vaccination was shown to be a useful method for inducing specific immune responses (20-24), and DNA vaccination is in human clinical trials (25-29). We now report that DNA vaccination with the CD25 gene can protect rats from AA induction. CD25 DNA vaccination was associated with modification of the antiergotypic response and influenced the $T$ cell proliferative response and cytokine phenotypes of both the antiergotypic response and the response to target antigens associated with AA.

\section{Methods}

Rats. Female Lewis rats were raised and maintained under pathogen-free conditions in the Animal Breeding Center of the Weizmann Institute. Experiments were carried out under the supervision and guidelines of the Animal Welfare Committee. The rats were 4-6 weeks old at the beginning of the experiments.

Plasmids and DNA vaccination. The coding sequence for the $\alpha$-chain of the rat IL-2 receptor (IL-2Ra; CD25) was cloned into the pcDNA3 expression vector (Invitrogen Corp., San Diego, California, USA) in the BamHI-XbaI sites. The $\gamma$-chain of the IL-2 receptor (IL-2Rg) CD132, which is constitutively expressed on T cells (8-10), was cloned in the BamHI-XhoI sites. The empty pcDNA3 vector was used as a control. Plasmid DNA was prepared in large scale using the Qiagen Plasmid Maxi Kit (QIAGEN GmbH, Hilden, Germany). DNA was eluted to a final concentration of $1 \mathrm{mg} / \mathrm{ml}$. In each experiment, groups of eight rats were injected intramuscular- 
ly in the quadriceps with $100 \mathrm{ml} /$ rat of $10 \mathrm{mM}$ cardiotoxin (SigmaAldrich, St. Louis, Missouri, USA) to increase the efficiency of DNA uptake (21). Three DNA vaccinations of $100 \mathrm{mg}$ each were given to each rat in the same site at 10-day intervals, beginning 5 days after the cardiotoxin injection.

$A A$ induction and scoring. Heat-killed Mycobacterium tuberculosis (Mt) strain H37Ra (Difco Laboratories, Detroit, Michigan, USA) was finely ground using a pestle and mortar and suspended to a final concentration of $10 \mathrm{mg} / \mathrm{ml}$ in incomplete Freund's adjuvant. To induce AA, rats were injected at the base of the tail with $100 \mathrm{ml}$ of the suspension containing $1 \mathrm{mg}$ of $\mathrm{Mt}$. AA was scored by direct observation of the four limbs in each animal (19). A relative score between 0 and 4 was assigned to each limb, based on the degree of joint inflammation, redness, and deformity. The maximum possible score for an individual rat was 16 . AA was also quantified by measuring the hindlimb ankle diameter with a caliper on day 26 . The disease reached its peak severity between days 22 and 26 .

Stimulator T cells. For ergotypic or control stimulation we used the Lewis rat A6 and A2b T cell clones: A6 is specific for myelin basic protein (MBP) (30) and A2b is specific for the $\mathrm{p} 180-188$ peptide of the $65-\mathrm{kDa}$ heat shock protein of $\mathrm{Mt}(31,32)$. The T cells were irradiated (50 Gy) before use in culture (see below). T cell-stimulation medium was composed of DMEM supplemented with 2-mercaptoethanol (2-ME) $\left(5 \times 10^{-5} \mathrm{M}\right)$, L-glutamine $(2 \mathrm{mM})$, sodium pyruvate $(1 \mathrm{mM})$, penicillin $(100 \mathrm{U} / \mathrm{ml})$, streptomycin $(100 \mathrm{mg} / \mathrm{ml})$, nonessential amino acids $(1 \mathrm{ml} / 100 \mathrm{ml}), 1 \%$ autologous serum, and $10 \mathrm{mg} / \mathrm{ml}$ of the specific antigen, guinea pig MBP (A6) or p180 peptide (A2b). After 3 days of stimulation, the $T$ cells were transferred to the rest medium as above, but without the stimulator antigen and containing 10\% FCS instead of autologous rat serum and 10\% TCGF ( $T$ cell growth factors) prepared from the supernatant of concanavalin A-activated (conA-activated) spleen cells (33). Activated $\mathrm{T}$ cells were used on day 3 of their stimulation to induce antiergotypic responses. Resting A6 T cells (A6-R) were used as controls on day 7-10 of their rest cycle, and resting A2b cells were used on day 14-21 of their rest cycle.

Adoptive transfer of antiergotypic T cells. Naive Lewis rats were vaccinated with $5 \times 10^{6}$ activated or resting (control) irradiated A2b cells (of Lewis rat origin) into each hind footpad. Popliteal LN cells were removed 7 days later and restimulated in vitro $\left(5 \times 10^{6} / \mathrm{ml}\right)$ with activated or resting irradiated T cells of the syngeneic D9 (MBP-specific) T cell line $\left(10^{6} / \mathrm{ml}\right)$. After 3 days in culture, the antiergotypic $\mathrm{T}$ cells and the control cells (stimulated with the resting $\mathrm{T}$ cells) were harvested, washed, and injected intraperitoneally, $10 \times 10^{6}$ per rat. A second injection of $5 \times 10^{6}$ antiergotypic or control T cells was given 10 days later, and on the same day AA was induced.

$T$ cell line. A line of T cells reactive to an immunogenic CD25 peptide a2 (see below) was raised from Lewis rats as described (13). This line was found to be $\mathrm{CD}^{+}$and MHC II restricted (not shown).

$A A$-associated target antigens. Target antigens associated with AA were the purified protein derivative (PPD) of Mt (Statens Seruminstitut, Copenhagen, Denmark) and the p180 peptide of $\mathrm{Mt}$ heat shock protein 65 (HSP65) composed of amino acids 176-190: EESNTFGLQLELTEG (32).

CD25 peptides as target antigens. CD25 immunogenic peptide antigens used in the proliferation experiments were described elsewhere (13). The sequences are a1, TTDTQKSTQSVYQEN-LAGHCR, and a2, ASEESQGSRNSFPESEACPT. The control peptide p53-1 is composed of the first 20 amino acids of the p53 protein (MTAMEESQSDISLELPLSQE).
Assay of proliferation and effects of anti-MHC Ab's. Draining lymph node (DLN) cells (inguinal and popliteal) were pooled from three rats of each experimental group and cultured in quadruplicates, $2 \times 10^{5} / 200 \mu \mathrm{l}$ in round-bottom microtiter wells (Nunc A/S, Roskilde, Denmark). Peptide p180, a1, a2, or PPD antigen were used at a final concentration of $10 \mu \mathrm{g} / \mathrm{ml}$, and conA was used at a concentration of $1.25 \mu \mathrm{g} / \mathrm{ml}$ as a positive control for $\mathrm{T}$ cell proliferation. The mAb's $(10 \mu \mathrm{g} / \mathrm{ml})$ to MHC class I and MHC class II (Serotec Ltd., Oxford, United Kingdom) were added where indicated to test for $\mathrm{MHC}$ restrictions of antiergotypic $\mathrm{T}$ cells. In the $\mathrm{T}$ cell coculture proliferations, A6 or A2b T cells were irradiated (50 Gy) and added to the test cultures in twofold dilutions, starting from $5 \times 10^{4}$ cells per well. Stimulation medium was composed of DMEM supplemented with 2-ME $\left(5 \times 10^{-5} \mathrm{M}\right)$, L-glutamine $(2 \mathrm{mM})$, sodium pyruvate $(1 \mathrm{mM})$, penicillin $(100 \mathrm{U} / \mathrm{ml})$, streptomycin $(100$ $\mu \mathrm{g} / \mathrm{ml})$, nonessential amino acids $(1 \mathrm{ml} / 100 \mathrm{ml})$, and $1 \%$ autologous serum. Cultures were incubated for 72 hours at $37^{\circ} \mathrm{C}$ in humidified air containing $7 \% \mathrm{CO}_{2}$. Each well was pulsed with $1 \mu \mathrm{Ci}$ of $\left[{ }^{3} \mathrm{H}\right]$ thymidine (Amersham International, Amersham, United Kingdom) for the last 16 hours. The cultures were then harvested, and counts per minute were determined using a beta counter. The stimulation index (SI) was calculated as the ratio of the mean counts per minute for each quadruplicate (containing the test antigen) to the mean counts per minute of spontaneous proliferation (wells containing LN cells without antigen).
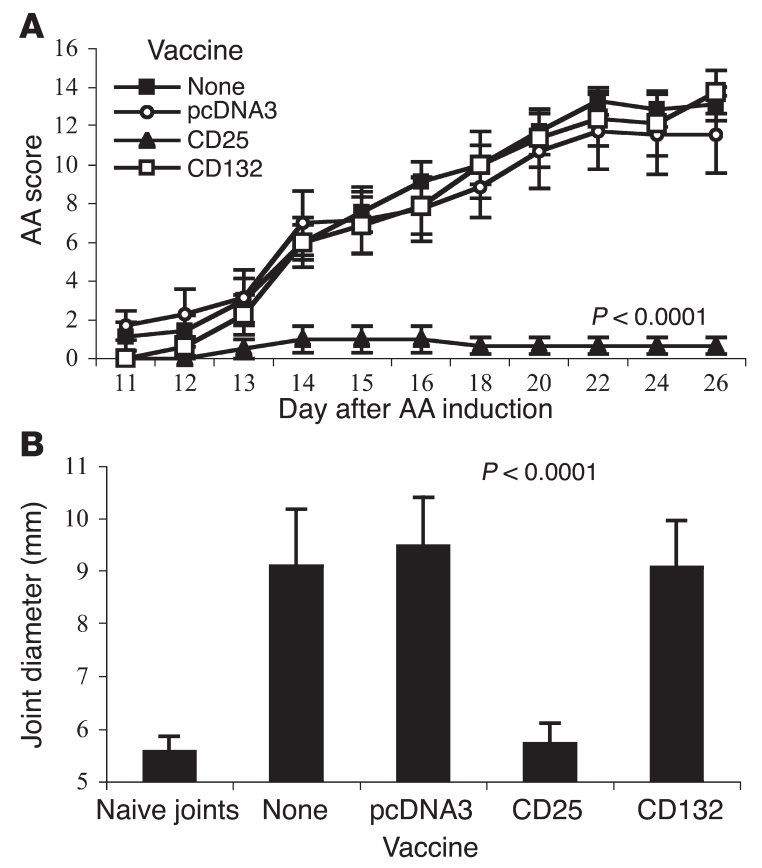

\section{Figure 1}

CD25 DNA vaccination protects against AA. (A) Groups of eight rats each were untreated, vaccinated with the empty vector (pcDNA3), the CD25 gene, or the CD132 gene, prior to AA induction (day 0). AA scores were assessed every day or two starting at day 11 . The mean \pm SEM disease score is shown. Scores of the CD25-vaccinated group were significantly reduced compared with the pcDNA3 group for each of the days 14-26 $(P<0.01)$. The $P$ value of day 26 is indicated. This is a representative experiment of three repetitions. (B) Ankle swelling measured at day 26 after AA induction. The results are presented in millimeters, mean \pm SEM, measured for the hindlimb ankle diameter. The $P$ value compares the CD25 and pcDNA3 groups. 


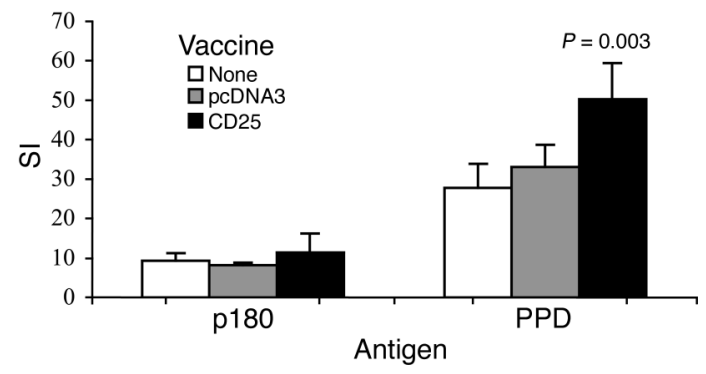

Figure 2

T cell proliferation in response to AA antigens. DLN cells from each of the three groups, nontreated (mean spontaneous proliferation $[\mathrm{MSP}]=$ $159 \mathrm{cpm}$ ), pcDNA3-vaccinated (MSP = $198 \mathrm{cpm}$ ), and CD25-vaccinated $(\mathrm{MSP}=223 \mathrm{cpm})$ were pooled from three rats, and their responses were measured on day 22 after AA induction. Stimulating antigens were PPD or the $\mathrm{p} 180$ peptide of Mt HSP65. Proliferative responses are presented as the $\mathrm{SI} \pm \mathrm{SEM}$ of quadruplicate cultures. Proliferation to PPD of DLN cells from CD25-vaccinated rats was significantly higher $(P=0.003)$ than that of pcDNA3-vaccinated rats. This is a representative experiment of three repetitions.

Purification of $\mathrm{CD}^{+}, \mathrm{CD} 8^{+}, \mathrm{T}$ cell receptor $\gamma / \delta^{+}$, and $\mathrm{T}$ cell receptor $\alpha / \beta^{+} C D 8^{+}$Tcells. CD4 ${ }^{+}, \mathrm{CD}^{+}$, and T cell receptor $\gamma / \delta^{+}\left(\mathrm{TCR} \gamma / \delta^{+}\right) \mathrm{T}$ cells were purified from DLNs by magnetic separation, using MACS antirat-specific MicroBeads and the LS-type column (Miltenyi Biotec $\mathrm{GmbH}$, Bergisch-Gladbach, Germany), according to the manufacturer's protocol. Cells were passed twice on two columns (four purification steps) to achieve more than $99 \%$ purity and then were checked by flow cytometry. Purified TCR $\alpha / \beta^{+} \mathrm{CD} 8^{+} \mathrm{T}$ cells were obtained by first purifying the TCR $\gamma / \delta^{+}$from whole DLN cells, followed by the purification of the $\mathrm{CD}^{+} \mathrm{T}$ cells from the TCR $\gamma / \delta^{+}$-depleted flow through. In this way we obtained purified $\mathrm{CD}^{+} \mathrm{T}$ cells containing only $0.08 \% \mathrm{TCR} \gamma / \delta^{+} \mathrm{T}$ cells compared with $5-6 \% \mathrm{TCR} \gamma / \delta^{+}$cells in the $\mathrm{CD}^{+} \mathrm{T}$ cells that had been purified from whole DLN cells. The purified cells were immediately used for proliferation assays.

Cytokine assays. Supernatants from the $\mathrm{T}$ cell proliferation experiments were collected at 72 hours. Rat IFN- $\gamma$, IL-10, and IL-4 were quantified by ELISA using OPTEIA kits for each of the cytokines (PharMingen, San Diego, California, USA), following the manufacturer's protocols. Rat TGF- $\beta 1$ was quantified using the TGF- $\beta 1$ $\mathrm{E}_{\max }$ ImmunoAssay System (Promega Corp., Madison, Wisconsin, USA) according to the manufacturer's instructions.

Statistical significance. The InStat 2.01 software was used for statistical analysis. Student's $t$ test and the Mann-Whitney test were carried out to assay the differences between experimental groups.

\section{Results}

$D N A$ vaccination with $C D 25$ protects from $A A$. We vaccinated Lewis rats with DNA encoding the CD25 gene. As controls, we vaccinated rats with the empty vector (pcDNA3) or with DNA encoding the constitutively expressed IL-2R $\gamma$-chain (CD132). AA was induced after three DNA vaccinations. Figure 1A shows that rats vaccinated with the pcDNA3 empty vector or with CD132 DNA developed the same level of disease as did unvaccinated control rats. In contrast, rats vaccinated with the CD25 gene were protected from AA. Protection was also detected by comparing the degree of ankle swelling, shown in Figure 1B. Thus, DNA vaccination with the CD25 ergotope was effective in protecting rats from AA.

Effect of DNA vaccination on $T$ cell proliferation to AA antigens. We tested whether protective CD25 DNA vaccination might modify $\mathrm{T}$ cell immunity to antigens associated with AA: the $\mathrm{p} 180$ peptide of mycobacterial HSP65 and PPD. Peptide p180 was found to be the target of arthritogenic T cells in AA (32), and PPD contains a mixture of mycobacterial antigens. Twenty-two days after AA induction, DLN cells were taken from the three groups and stimulated in vitro using either of the two antigens. As can be seen in Figure 2 , there was no significant difference between the three groups in their $\mathrm{T}$ cell proliferation to the $\mathrm{p} 180$ peptide. $\mathrm{T}$ cell proliferation to PPD was significantly increased, however, in the protected rats vaccinated with the CD25 gene.

Protection is associated with a cytokine shift from a Th1-like to a Th2-like phenotype. To study the effect of CD25 DNA vaccination on the cytokine profile, we analyzed media taken from the proliferating T cells described above. Figure 3 shows the results: DLN cells from the untreated control AA rats secreted high levels of IFN- $\gamma$ (Figure $3 \mathrm{~A})$ in response to stimulation with the $\mathrm{p} 180$ peptide or with PPD. DLN cells from animals vaccinated with the empty pcDNA3 vector, although not protected, secreted less IFN- $\gamma$. Note, however, that there was a significant decrease in IFN- $\gamma$ secretion by cells taken from the CD25-protected rats. The opposite pattern was detected when we tested the same cells for the secretion of IL-10, a Th2 cytokine. Control groups secreted low levels of IL-10 in response to PPD or $\mathrm{p} 180$, but the CD25 DNA-vaccinated group, protected from the disease, exhibited a significant increase in IL-10 secretion (Figure 3B). Secretion of IL-4 or TGF- $\beta$ was not detectable in these samples.

Antiergotypic T cells protect rats from AA induction. In these studies, we could detect very little anti-CD25 Ab in the sera of CD25 DNAvaccinated rats (not shown). Thus, we questioned whether anoth-
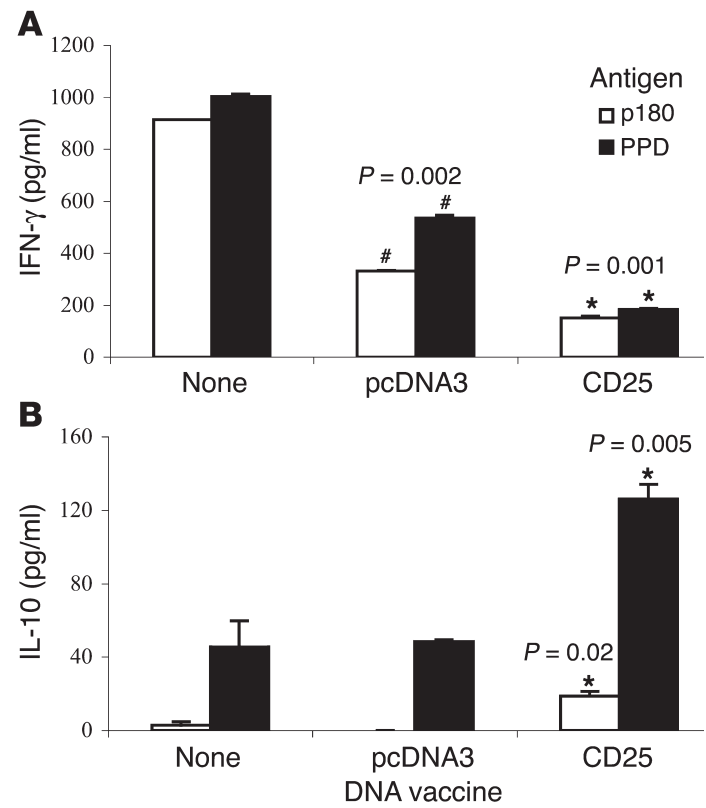

\section{Figure 3}

Cytokine secretion by DLN cells proliferating to AA antigens. The media of the proliferating DLN cells of the three groups described in Figure 2, nontreated, pcDNA3-vaccinated, and CD25-vaccinated, responding to PPD or p180, were taken after 72 hours in culture and analyzed by ELISA for (A) IFN- $\gamma$ or (B) IL-10. The results are presented as picograms per milliliter. This is a representative experiment of three repetitions. ${ }^{*} P$ value in comparison with pcDNA3-vaccinated group; ${ }^{P} P$ value in comparison with the nontreated group. 


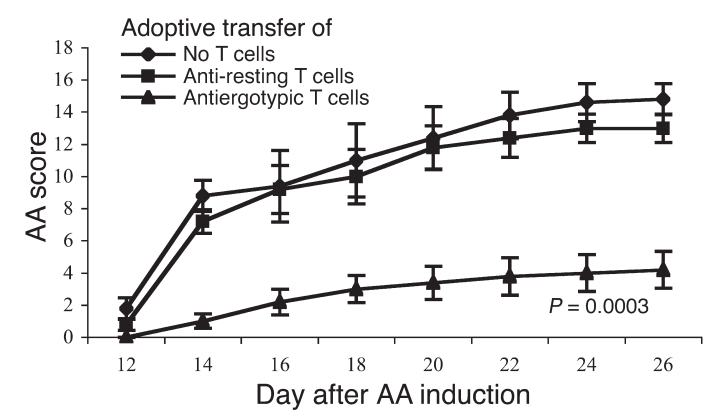

Figure 4

Adoptive transfer of antiergotypic T cells protects from AA. Antiergotypic $T$ cells were obtained from the DLN of rats vaccinated with irradiated, activated, syngeneic A2b T cells. Control cells were obtained from rats vaccinated with resting $A 2 b \mathrm{~T}$ cells. The antiergotypic $L N$ cells and control LN cells were stimulated in vitro with activated or resting D9 T cells, respectively. Naive rats were injected with $10 \times 10^{6}$ antiergotypic $T$ cells or control $T$ cells. Ten days later the rats were boosted with $5 \times 10^{6}$ cells, and AA was induced on the same day (day 0). AA scores were assessed every 2 days starting at day 12. The mean \pm SEM disease score is shown. Scores of the antiergotypic $T$ cell-vaccinated group were significantly reduced compared with the control T cell-vaccinated group for each of the days 14-26 $(P<0.01)$. The $P$ value of day 26 is indicated.

er protective mechanism might be associated with CD25 DNA vaccination. Because CD25 was found to serve as an ergotope (13), we investigated the possibility that the protection was as a result of an antiergotypic response. At first, we studied whether antiergotypic $\mathrm{T}$ cells could protect rats from AA induction: antiergotypic $\mathrm{T}$ cells were obtained from the DLN of rats vaccinated with irradiated, activated syngeneic A2b T cells. Control cells were obtained from rats vaccinated with resting A2b T cells. The antiergotypic LN cells and control LN cells were stimulated in vitro with activated or resting $\mathrm{D} 9 \mathrm{~T}$ cells, respectively, and injected in rats. As can be seen in Figure 4, adoptive transfer of the antiergotypic $\mathrm{T}$ cells induced significant protection from AA; control rats that had received LN cells stimulated with resting D9 T cells were not protected. Thus, resistance to AA could be induced by the adoptive transfer of antiergotypic T cells.

Antiergotypic $T$ cells are present in naive rats and are downregulated upon AA induction. To study whether CD25 DNA vaccination could enhance antiergotypic reactivity, we compared the antiergotypic responses of AA rats with those of rats protected by the CD25 DNA. We first tested whether there existed a basal antiergotypic activity and whether it might be affected by the induction of AA, an autoimmune disease associated with $\mathrm{T}$ cell activation (19). Naive LN cells collected from inguinal and popliteal LNs were cocultured with irradiated A6 T cells, either activated or resting, to test their antiergotypic response. Figure $5 \mathrm{~A}$ shows that the naive LN cells exhibited a natural antiergotypic response to stimulated A6 T cells (A6-S), but not to A6-R. The highest response was against 50,000 stimulator cells. The response to 100,000 cells exhibited a prozone effect, an overstimulation resulting in a lower response (not shown). The same experiment was then done with DLN cells taken from rats after AA induction. As can be seen in Figure $5 \mathrm{~B}$, the induction of AA was associated with downregulation of the natural antiergotypic response, reaching its lowest levels at the peak of the disease.
Protection from AA is associated with preservation of the antiergotypic proliferative response. To relate the mechanism of protection by CD25 vaccination to the induction of the antiergotypic response, DLN cells from the rats were studied for their ability to proliferate in response to activated or resting syngeneic $\mathrm{T}$ cells. We studied two different time points after DNA vaccination with CD25 or pcDNA3: before AA induction (Figure 6, A and B) or at day 22 after AA induction (Figure 6, C and D). As stimulators we used the A6 T cell clone, A6-S or A6-R (30). As can be seen in Figure 6, A and B, before AA induction neither the CD25 (Figure 6B) nor the pcDNA3 (Figure 6A) DNA vaccines could amplify the natural antiergotypic response found in naive rats (compare Figure 6, A and B, with Figure $5 \mathrm{~A}$ ). The difference between the groups was found only after the induction of AA. In the group that had been vaccinated with the pcDNA3 vector, a significant decrease in the antiergotypic proliferative response was observed (Figure 6C), similar to that found in naive rats undergoing AA. Nevertheless, the group vaccinated with CD25 DNA retained their antiergotypic proliferative response to activated A6 T cells (Figure 6D). In contrast to the response found in the naive LN cells, the highest response in the CD25-protected rats was against 25,000 stimulator cells. The sensitivity of the prozone effect appeared to have been shifted, since only a low response was found against 50,000 cells. Thus, effective DNA vaccination with the CD25 gene prevented the decline of the natural antiergotypic proliferation response that otherwise accompanies AA.

Vaccination with CD25 DNA induces T cell responses to peptides of CD25. To investigate whether CD25 DNA vaccination might induce a T cell response to CD25 epitopes, we used the two immunogenic peptides of CD25 (13) as antigens in proliferation assays. Rats were vac-

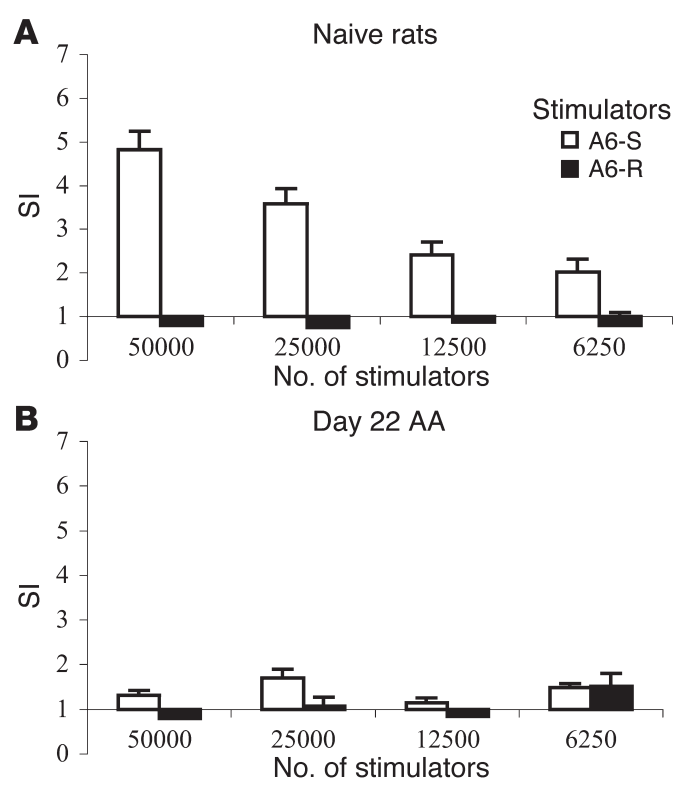

Figure 5

The antiergotypic $T$ cell response in naive rats is downregulated by $A A$ induction. $L N$ cells from $(A)$ naive rats $(M S P=153 \mathrm{cpm})$ or $(B) D L N$ cells from rats at day 22 of $A A$ induction $(M S P=159 \mathrm{cpm})$ were pooled from three rats and were measured for the T cell response to A6-S or A6-R at different stimulator cell concentrations. The decrease in the response to activated T cells is significant: $P<0.02$ for all stimulator cell concentrations, compared with the naive rats $(\mathbf{A})$. Proliferative responses are presented as the $\mathrm{SI} \pm \mathrm{SEM}$ of quadruplicate cultures. This is a representative experiment of three repetitions. 
A

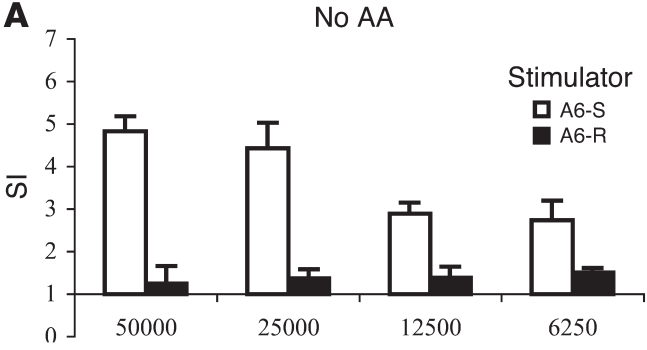

C

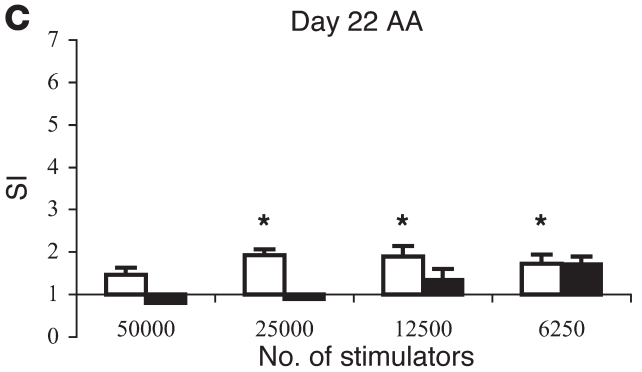

B

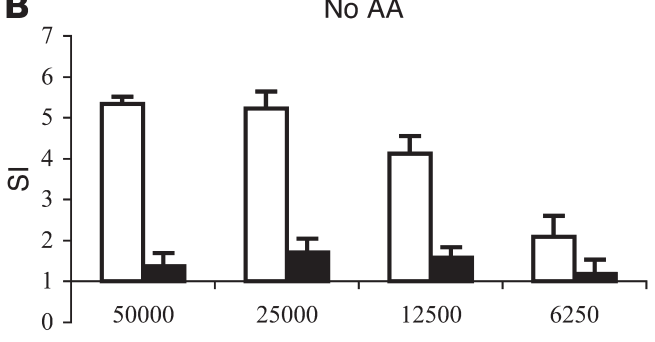

D

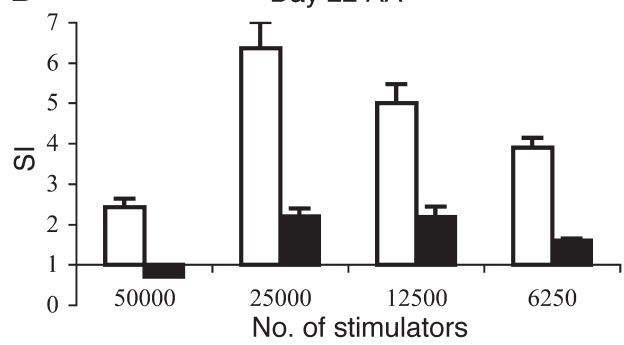

Figure 6

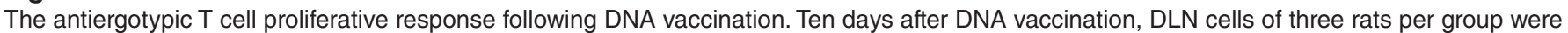

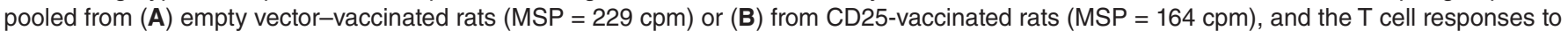

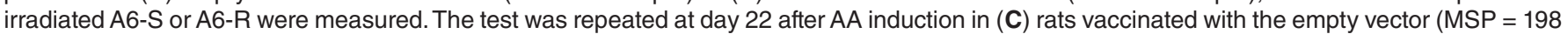

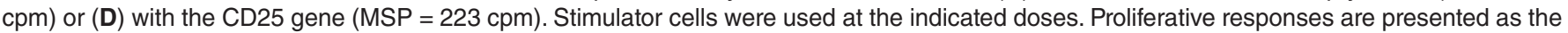

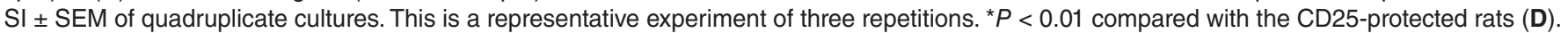

cinated with CD25 DNA. Control groups were vaccinated with the pcDNA3 empty vector, with the CD132 gene (IL-2Rg, which is not an ergotope), or were not vaccinated, and AA was induced. On day 22 of AA, we found that DLN cells taken from the three control groups exhibited insignificant levels of proliferation to each of the two peptides. DLN cells from the group vaccinated with the CD25 gene exhibited a significant response to the CD25 peptides (Figure 7), however. No proliferation to the nonrelated p53 control peptide was observed. Thus, we can conclude that DNA vaccination with the CD25 gene induced a $T$ cell response to CD25 peptides.

Cytokine profile of the antiergotypic Tcells. To document the cytokines secreted by antiergotypic $\mathrm{T}$ cells obtained from immunized rats, DLN cells were stimulated by activated or resting A6 T cells at two time points: 10 days after the third DNA vaccine (before AA induction) and on day 22 of AA. Culture media were analyzed for the presence of IFN- $\gamma$, IL-10, IL-4, and TGF- $\beta$. DNA vaccination alone, which did not affect the proliferative responses of the antiergotypic T cells (Figure 6, A and B), also did not induce cytokine secretion (not shown). Nevertheless, as can be seen in Figure 8, the induction

\section{Figure 7}

DNA vaccination with CD25 induces $T$ cell responses to CD25 peptides in protected rats. DLN cells from each of the four groups, nontreated $(\mathrm{MSP}=159 \mathrm{cpm})$, pcDNA3-vaccinated $(\mathrm{MSP}=198 \mathrm{cpm})$, CD25-vaccinated $(M S P=223 \mathrm{cpm})$, and CD132-vaccinated $(M S P=305 \mathrm{cpm})$, were pooled from three rats, and their antiergotypic responses were measured on day 22 after AA induction. Two $\alpha$-chain (a1, a2) peptides were used as ergotopes. A control peptide from the p53 protein (p53-1) was included. Proliferative responses are presented as the SI \pm SEM of quadruplicate cultures. ${ }^{*} P<0.02$ compared with the nonprotected CD132-vaccinated group for the two peptides. of AA was associated with cytokine secretion by antiergotypic T cells: DLN cells from nonprotected control groups (both nontreated and pcDNA3 vaccinated) secreted mainly IFN- $\gamma$ and only low levels of IL-10. In contrast, DLN cells from protected rats immunized with CD25 DNA proliferated to activated T cells and secreted significantly increased amounts of IL-10 and only low levels of IFN- $\gamma$ (Figure 8, A and B). Indeed, there was some increase of IL-10 secretion even to A6-R, relative to the control-vaccinated rats. Neither IL-4 nor TGF- $\beta$ were detected in these samples. Thus, protection induced by DNA vaccination with CD25 was associated with upregulation of antiergotypic T cells secreting IL-10 and by the downregulation of antiergotypic T cells secreting IFN- $\gamma$.

The phenotype of antiergotypic $T$ cells in protected rats. To characterize the phenotype of the antiergotypic $\mathrm{T}$ cells in the protected rats, we took the DLNs at day 22 after AA induction, purified the $\mathrm{CD}^{+}$, $\mathrm{CD}^{+}, \mathrm{CD} 8^{+} \mathrm{TCR} \alpha / \beta^{+}$, and TCR $\gamma / \delta^{+}$populations, and checked their proliferation to activated A2b T cells. As can be seen in Figure 9, both $\mathrm{CD}^{+}$and $\mathrm{CD}^{+} \mathrm{T}$ cells proliferated in response to activated $\mathrm{T}$ cells, although the $\mathrm{CD}^{+}$response was stronger. Moreover, puri- 
A

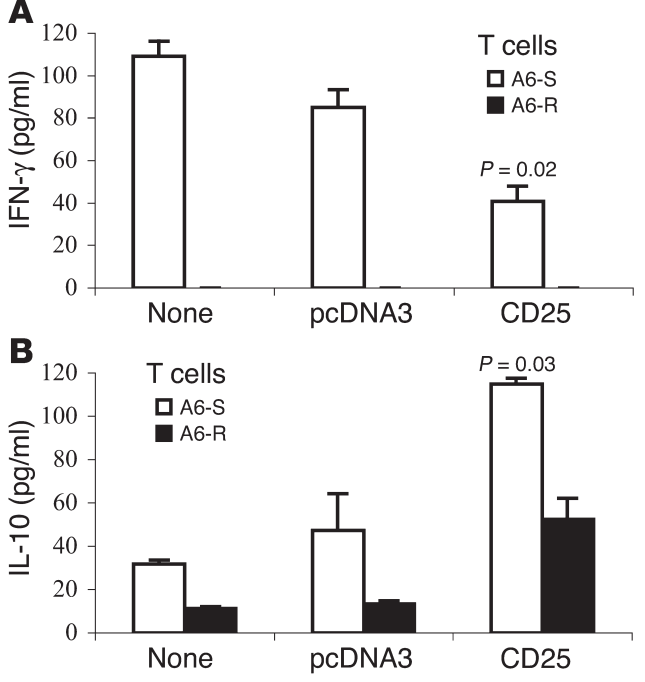

fied TCR $\gamma / \delta^{+}$T cells (of which $83-86 \%$ were $C D 8^{+} \mathrm{TCR} \gamma / \delta^{+}$, as found by FACS analysis; not shown) proliferated twice as strongly as did equal numbers of the CD8 ${ }^{+} \mathrm{TCR} \alpha / \beta^{+}$cells. Since $99 \%$ of the $\mathrm{CD} 4^{+}$ T cells were TCR $\alpha / \beta^{+}$, we could not isolate enough CD $4^{+} \mathrm{TCR} \gamma / \delta^{+}$ for testing. No response to resting A2b cells was detected (not shown). Thus, antiergotypic $\mathrm{T}$ cells, which are associated with resistance to $\mathrm{AA}$, are present in both the $\mathrm{CD}^{+}$and $\mathrm{CD}^{+}$populations and can express $\alpha / \beta$ or $\gamma / \delta$ T cell receptors; the $\gamma / \delta$ TCR population is relatively enriched for antiergotypic cells.

$M H C$ restriction of the different antiergotypic T cell populations. The MHC restriction of the $\mathrm{CD}^{+}, \mathrm{CD}^{+}, \mathrm{CD}^{+} \mathrm{TCR} \alpha / \beta^{+}$, and TCR $\gamma / \delta^{+}$antiergotypic $\mathrm{T}$ cell populations, obtained from protected rats, was investigated by studying the effects of different anti-MHC Ab's on the proliferation of antiergotypic T cells to activated A2b cells. We took the DLNs from CD25 DNA-vaccinated rats at day 22 after AA induction and separated the $\mathrm{T}$ cells into various subsets. As shown in Table 1, the response of the $\mathrm{CD}^{+}$antiergotypic $\mathrm{T}$ cells was inhibited by the anti-MHC II (I-A) $\mathrm{mAb}$, and the response of the $\mathrm{CD} 8^{+}$antiergotypic $\mathrm{T}$ cells was inhibited by the anti-MHC I Ab. In contrast, the response of the TCR $\gamma / \delta^{+}$antiergotypic T cells, which was the strongest, was not $\mathrm{MHC}$ restricted, because it was not inhibited by any of the anti-MHC Ab's. The anti-MHC-II (I-E) Ab, which was used as a negative control (the A2b clone does not express I-E), did not affect the proliferation of any of the antiergotypic $T$ cell populations.

Anti-CD25 T cell line is antiergotypic. To test whether epitopes of CD25 are presented by activated T cells, we incubated a T cell line

\section{Figure 9}

The antiergotypic $T$ cell phenotypes in protected rats. Twenty-two days after $\mathrm{AA}$ induction, $\mathrm{CD} 4^{+}, \mathrm{CD} 8^{+}, \mathrm{CD} 8^{+} \mathrm{TCR} \alpha / \beta^{+}$, and $\mathrm{TCR} \gamma / \delta^{+} \mathrm{T}$ cells were purified from DLN cells taken from rats protected by the CD25 DNA vaccine. Equal numbers of the purified T cell populations were measured for their proliferative responses to activated irradiated syngeneic $T$ cells at different stimulator cell concentrations. Proliferative responses are presented as the change in counts per minute $(\Delta \mathrm{cpm}) \pm$ SEM of quadruplicate cultures. ${ }^{*} P<0.02$ compared with the purified CD4+ proliferative response; ${ }^{\#} P<0.01$ compared to the response of the CD8 ${ }^{+} \mathrm{TCR} \alpha / \beta^{+} \mathrm{T}$ cells.

\section{Figure 8}

Cytokine secretion by antiergotypic T cells. The media of the DLN cells of the three groups described in Figure 7, nontreated, pcDNA3 vaccinated, and CD25 vaccinated, responding to A6-S or A6-R at day 22 of AA induction were taken after 72 hours in culture and analyzed by ELISA for (A) IFN- $\gamma$ or (B) IL-10. The results are presented in picograms per milliliter. This is a representative experiment of three repetitions. The $P$ values indicate a significant decrease in IFN- $\gamma$ secretion and an increase in IL-10 secretion compared with rats vaccinated with the empty vector.

specific for the a2 CD25 peptide with activated or resting syngeneic irradiated $\mathrm{T}$ cell line and followed its proliferation. Figure 10 exhibits the strong proliferation of the anti-CD25 $\mathrm{T}$ cell line against the activated $\mathrm{A} 2 \mathrm{~b} \mathrm{~T}$ cells. No response was detected to resting A2b T cells (Figure 10). Similar results were obtained in a parallel experiment (not shown) performed with an additional $\mathrm{T}$ cell line specific for a different CD25 peptide (peptide a1). Thus, it appears that activated $T$ cells can present at least two peptide epitopes of CD25 to syngeneic antiergotypic T cells. Thus, CD25 can behave as an ergotope. A control T cell line responsive to MBP did not respond to $\mathrm{A} 2 \mathrm{~b} \mathrm{~T}$ cells irrespective of whether they were activated or resting (not shown).

\section{Discussion}

Immunosuppression can be achieved by inhibiting the interaction between IL-2 and its receptor. Thus, mAb's are used clinically for blocking the IL-2 receptor and inhibit the proliferation of effector T cells. Regulatory $\mathrm{T}$ cells, too, can control $\mathrm{T}$ cell reactions. Over the last decade, evidence has accumulated regarding different populations of regulatory T cells (34-39). Relatively little is known about antiergotypic regulatory $\mathrm{T}$ cells, however. Here we studied the effect of an immune response to CD25, an ergotope, on the induction of AA.

During the course of these experiments, we made the following observations (tabulated, in part, in Table 2): (a) DNA vaccination with a specific ergotope, the CD25 gene, protected rats from AA; (b) Protection was associated with a shift from Th1 toward Th2 in the

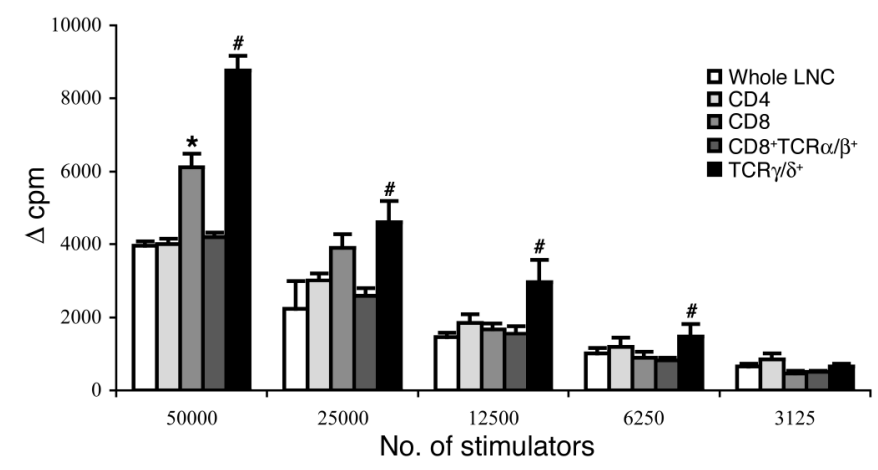


Table 1

Anti-MHC Ab's inhibit antiergotypic T cell proliferation

\begin{tabular}{|c|c|c|c|}
\hline \multirow[t]{2}{*}{ Cells } & \multicolumn{3}{|c|}{ Inhibition of proliferation (\%) } \\
\hline & MHC I & MHC II I-A & MHC II I-E \\
\hline Whole LNCs & 61 & 43 & 7 \\
\hline $\mathrm{CD}^{+}+$ & 6 & 88 & 2 \\
\hline $\mathrm{CD}^{+}$ & 87 & 4 & 0 \\
\hline $\mathrm{CD} 8{ }^{+}{ }^{+} \mathrm{CR} \alpha / \beta^{+}$ & 90 & 4 & 2 \\
\hline $\mathrm{TCR} \gamma / \delta^{+}$ & 1 & 1 & 5 \\
\hline
\end{tabular}

DLN cells were pooled from three CD25 DNA-vaccinated rats 22 days after AA induction and assayed for the effects of anti-MHC Ab's on their proliferation to activated $\mathrm{A} 2 \mathrm{~b}$ T cells. This is a representative experiment of three repetitions.

cytokine phenotype of the $\mathrm{T}$ cell response to AA-associated target antigens; (c) adoptive transfer of antiergotypic $\mathrm{T}$ cells protected rats from AA; (d) antiergotypic T cells responding to whole $\mathrm{T}$ cells could be detected in naive rats; (e) AA induction in untreated rats downregulated the proliferation of antiergotypic T cells; (f) in CD25-vaccinated rats, protection against AA was associated with retention of the antiergotypic proliferative response to whole activated $T$ cells and with T cell proliferation to CD25 peptides; (g) activated T cells (but not resting $\mathrm{T}$ cells) could present CD25 epitopes to other $\mathrm{T}$ cells; (h) antiergotypic T cells taken from nonprotected control rats secreted mainly IFN- $\gamma$, while antiergotypic cells taken from CD25protected rats secreted decreased amounts of IFN- $\gamma$ and increased amounts of IL-10; (i) the antiergotypic T cells taken from the CD25protected rats included both $\mathrm{CD}^{+}$or $\mathrm{CD}^{+}$populations and expressed both the $\alpha / \beta$ or $\gamma / \delta$ TCR; (j) the response of the $C D 4^{+}$ antiergotypic $\mathrm{T}$ cells was $\mathrm{MHC}$ class II restricted and the $\mathrm{CD} 8^{+} \mathrm{TCR} \alpha / \beta^{+}$response was class I restricted. The TCR $\gamma / \delta^{+}$antiergotypic response was not $\mathrm{MHC}$ restricted.

Interestingly, the existence of a natural antiergotypic proliferative response in naive rats did not protect them from the induction of AA. On the contrary, the induction of AA led to downregulation of this natural antiergotypic response. To protect rats from AA, the antiergotypic response had to be further activated by DNA vaccination with CD25.

The effect of CD25 DNA vaccination on the phenotype of the immune response to AA target antigens was interesting: protection was associated with significantly higher levels of proliferation to PPD. Increased proliferation to mycobacterial antigens has been described by us (40) and others (41-44) in experiments in which HSP60 or HSP65 was administered to induce resistance to AA. This increased proliferation suggests that AA protection might be related to the cytokines secreted by the responding $\mathrm{T}$ cells, rather

\section{Figure 10}

Anti-CD25 T cell line proliferates to activated but not to resting T cells. T cell lines specific for the a2 peptide of CD25 were tested for their $T$ cell proliferative response to activated (A2b-S) or resting (A2b-R) syngeneic, irradiated $T$ cells at different stimulator cell concentrations. Proliferative responses are presented as the averaged change in counts per minute $(\Delta \mathrm{cpm})$ of quadruplicate cultures. This is a representative experiment of three repetitions. than to the level of their proliferation. Indeed, we found a Th1-like profile of cytokines in sick rats, while protected rats exhibited more of a Th2-like profile in response to AA target antigens.

It is interesting that vaccination with the pcDNA3 empty vector led to lower levels of IFN- $\gamma$, but did not prevent AA (Figure 3a). This decrease in IFN- $\gamma$ secretion may be related to the fact that an empty vector may affect $T$ cell responses due to $C p G$ sequences; vaccination with $\mathrm{CPG}$ sequences or pcDNA3 was shown to protect animals from EAE (45), diabetes (46), and colitis (47). Stimulation by the $\mathrm{CPG}$ sequences present in pcDNA3, however, apparently was not strong enough to inhibit AA.

The protection induced by CD25 DNA vaccination could be explained by at least two possibilities: either by the induction of anti-CD25 Ab's that block IL-2 binding or by the induction of an antiergotypic response. We could detect little or no anti-CD25 Ab in the sera of CD25 DNA-vaccinated rats (not shown). Thus, antiCD25 Ab's, if they played any role in protection in these experiments, had to be effective even at very low concentrations. In contrast, following the protocol used by Lohse and coworkers for EAE (11), we found that antiergotypic T cells could protect rats from AA induction. Thus, we examined the induction of an antiergotypic response following CD25 DNA vaccination. Indeed, the antiergotypic responses differed markedly between the sick and the DNA-protected rats. The CD25 DNA vaccination itself did not cause a significant increase in the antiergotypic response to activated $\mathrm{T}$ cells (Figure $5 \mathrm{~b}$ ), and no cytokines were detected at this stage. The induction of AA, however, amplified the differences in the antiergotypic responses between protected and sick rats. The fact that $\mathrm{T}$ cell proliferation to CD25 peptides was detected only in the CD25 DNA-vaccinated rats (Figure 7) indicates that the CD25 DNA vaccine was immunogenic. The responses to the two available CD25 peptides were modest, and other, more stimulatory, CD25 peptides may yet be found. Nevertheless, activated T cells can present CD25 epitopes; CD25 functions as an ergotope.

In contrast to AA induced in pcDNA3-vaccinated rats, we found that the antiergotypic proliferative response to whole $T$ cells was preserved in the CD25 DNA-vaccinated rats. Although the levels of proliferation to whole $\mathrm{T}$ cells was preserved and did not increase in protected rats (compared with naive rats), antiergotypic $\mathrm{T}$ cell responses seemed to gain sensitivity following the protective DNA vaccine: the prozone effect seemed to be shifted from a maximal response against 50,000 cells in the naive rats to a maximal response against 25,000 stimulator cells in the CD25-protected rats. Apparently, too much ergotypic stimulation in vitro might be inhibitory.

Effective CD25 DNA vaccination together with AA induction led to increased IL-10 and decreased IFN- $\gamma$ produced by the antiergotypic $\mathrm{T}$ cells responding to whole activated T cells. How CD25

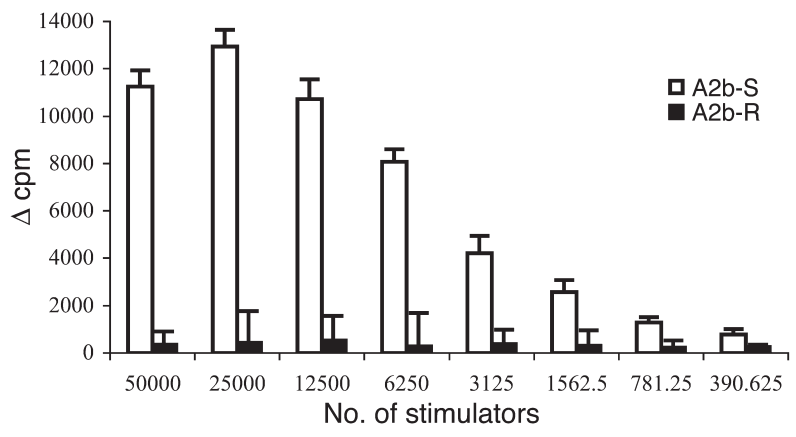


Table 2

Summary of findings

\begin{tabular}{|c|c|c|c|c|c|c|c|c|}
\hline \multirow[t]{3}{*}{ Vaccine } & \multirow[t]{3}{*}{ AA induction } & \multicolumn{3}{|c|}{ DLN cell proliferation to } & \multicolumn{4}{|c|}{ Cytokine secretion to } \\
\hline & & \multirow[t]{2}{*}{$\begin{array}{l}\text { Activated } \\
\text { T cells }\end{array}$} & \multirow[t]{2}{*}{$\begin{array}{l}\text { Resting } \\
\text { T cells }\end{array}$} & \multirow[t]{2}{*}{$\begin{array}{c}\text { AA } \\
\text { antigens }\end{array}$} & \multicolumn{2}{|c|}{$\begin{array}{l}\text { Activated } \\
\text { T cells }\end{array}$} & \multicolumn{2}{|c|}{$\begin{array}{c}\text { PPD, an } \\
\text { AA antigen }\end{array}$} \\
\hline & & & & & IFN- $\gamma$ & IL-10 & IFN- $\gamma$ & IL-10 \\
\hline \multirow[t]{2}{*}{ None } & - & + & - & - & - & - & - & - \\
\hline & + & - & - & + & 110 & 30 & 1,000 & 40 \\
\hline \multirow[t]{2}{*}{ pcDNA3 } & - & + & - & - & - & - & - & - \\
\hline & + & - & - & + & 90 & 50 & 600 & 40 \\
\hline \multirow[t]{2}{*}{ CD25 } & - & + & - & - & - & - & - & - \\
\hline & $+($ protected $)$ & + & $-/+$ & ++ & 40 & 120 & 200 & 120 \\
\hline
\end{tabular}

The table summarizes the results presented in Figures 2, 3, 5, 6, and 8. All proliferation experiments were performed by pooling LNs from three rats per group. All the experiments were repeated three times. Cytokine secretion is presented in picograms per milliliter.

DNA induces this change in cytokine profile remains to be analyzed. In any case, we suspect that the cytokine balance between the antiergotypic T cells and the AA-associated T cells may affect the cytokine environment and so influence the disease. In control-vaccinated rats, the arthritogenic $\mathrm{T}$ cells causing the disease seem to be the cells controlling the cytokine environment by secreting mainly the Th 1 cytokine IFN- $\gamma$. This Th 1 cytokine might also have an inhibitory effect on the activation of the antiergotypic T cells, which do not proliferate, but also secrete IFN- $\gamma$. In contrast, CD25 DNA vaccination boosted the antiergotypic $\mathrm{T}$ cells, preserving their antiergotypic proliferation and inducing IL-10 secretion. The IL-10 could help drive the differentiation of the otherwise pathogenic $T$ cells toward a Th2 phenotype.

Mor and colleagues previously demonstrated that a line of $\mathrm{T}$ cells specific for a peptide epitope of CD25 could induce resistance to EAE (13). The present results extend the connection between antiergotypic regulation and CD25 vaccination to the AA model and confirm that CD25 vaccination modulates the antiergotypic response. Technically, it has not been possible to raise stable antiergotypic T cell lines; the cultures, for unknown reasons, tend to die. Perhaps antiergotypic T cells suppress themselves in culture. Nevertheless, CD25 can behave as an ergotope in that anti-CD25 T cells can respond to activated T cells expressing CD25 (Figure 10). Taken together, the results in this paper are compatible with the idea that some antiergotypic $T$ cells indeed recognize CD25.

Note that we do not intend to suggest that CD25 is the only ergotope; naive rats manifest antiergotypic responses to activated syngeneic T cells, but no reactivity to CD25 peptides was detected until the rats had been vaccinated with CD25 DNA (Figure 7). Indeed, the presence of antiergotypic reactivity in $\mathrm{CD}^{+}, \mathrm{CD}^{+}$, $\mathrm{TCR} \alpha / \beta$, and TCR $\gamma / \delta$ subsets, with and without MHC I and MHC II restriction, indicates that antiergotypic reactions are heterogeneous and suggest that a variety of ergotopes could be targeted by $\mathrm{T}$ cells responsive to activated $\mathrm{T}$ cells.

Besides antiergotypic $\mathrm{T}$ cells, other regulatory $\mathrm{T}$ cells that use an IL-10-mediated mechanism include T regulatory $1(\operatorname{Tr} 1)$ cells $(48$, 49). $\operatorname{Tr} 1$ cells, however, suppress proliferation of antigen-specific autoimmune $T$ cells in contrast to the antiergotypic $T$ cells, which do not suppress $T$ cell proliferation but seem to induce a shift in cytokine phenotype.

A comparison of antiergotypic regulatory $\mathrm{T}$ cells to anti-idiotypic regulatory $\mathrm{T}$ cells reveals a difference in their cytokine profile. Anti-idiotypic cells, induced either by $\mathrm{T}$ cell vaccination or by TCR
$\mathrm{V}_{\beta}$ vaccination, secret Th1 cytokines $(16,50)$. The antiergotypic cells, in contrast, secrete mainly IL-10, a Th2 cytokine.

Finally, by isolating different phenotypes of T cells, we found antiergotypic $\mathrm{T}$ cells in both the $\mathrm{CD}^{+}$and $\mathrm{CD}^{+}$subsets. Moreover, antiergotypic T cells include both $\alpha / \beta$ and $\gamma / \delta$ TCR classes. Interestingly, the TCR $\gamma / \delta^{+} \mathrm{T}$ cells proliferated to activated T cells twice as strongly as did an equal number of TCR $\alpha / \beta^{+} \mathrm{T}$ cells. The biological role of TCR $\gamma / \delta^{+}$T cells is poorly understood generally. TCR $\gamma / \delta^{+}$T cells might have a regulatory function in organ-specific autoimmune diseases, possibly by regulating TCR $\alpha / \beta^{+}$autoreactive T cells (51): this was shown in experimental models such as NOD and MRL-lpr mice $(52,53)$. Further work is needed to elucidate the relationship between these regulatory TCR $\gamma / \delta^{+}$cells and the antiergotypic $\mathrm{T}$ cells we describe here. Interestingly, antiergotypic $T$ cells described following $T$ cell vaccination of multiple sclerosis patients were also of both the $\mathrm{CD}^{+}$and $\mathrm{CD} 8^{+}$phenotypes and also expressed both $\alpha / \beta$ and $\gamma / \delta$ TCRs $(17,54)$.

In this study, we vaccinated rats with a specific ergotope, the CD25 gene. CD25, however, is a well-known marker of another regulatory $\mathrm{T}$ cell subset, the $\mathrm{CD} 4^{+} \mathrm{CD} 25^{+} \mathrm{T}$ cells, which constitutively express $\mathrm{CD} 25$ (37). Unlike the $\mathrm{CD} 4^{+} \mathrm{CD} 25^{+}$regulatory $\mathrm{T}$ cells, which inhibit proliferation of $\mathrm{CD}^{+} \mathrm{T}$ cells $(35,37,55)$, we found that the induction of an antiergotypic $\mathrm{T}$ cell response did not suppress proliferation of the autoimmune $T$ cells, but was associated with a cytokine shift. It might be that both regulatory $\mathrm{T}$ cell subsets participate in controlling autoimmune $\mathrm{T}$ cells. While the $\mathrm{CD} 4^{+} \mathrm{CD} 25^{+}$ regulatory $\mathrm{T}$ cells suppress proliferation of autoimmune $\mathrm{T}$ cells, the antiergotypic T cells may encounter residual autoimmune proliferating $\mathrm{T}$ cells and push them toward a Th2 cytokine profile.

\section{Acknowledgments}

Irun R. Cohen is the incumbent of the Mauerberger Chair in Immunology. This study was supported by grants from the Minerva Foundation and from the Center for the Study of Emerging Diseases. We thank Danielle Sabah-Israel for devoted secretarial assistance.

Received for publication January 6, 2003, and accepted in revised form January 13, 2004.

Address correspondence to: Irun R. Cohen, Department of Immunology, The Weizmann Institute of Science, Rehovot 76100, Israel. Phone: 00972-08934-2911; Fax: 00972-08934-4103; E-mail: irun.cohen@weizmann.ac.il. 
1. Kirkman, R.L., et al. 1985. Administration of an antiinterleukin 2 receptor monoclonal antibody prolongs cardiac allograft survival in mice. J. Exp. Med. 162:358-362.

2. Kupiec-Weglinski,J.W., Diamantstein, T., and Tilney, N.L. 1988. Interleukin 2 receptor-targeted therapyrationale and applications in organ transplantation. Transplantation. 46:785-792.

3. Leist, T.P., Kohler, M., Eppler, M., and Zinkernagel, R.M. 1989. Effects of treatment with IL-2 receptor specific monoclonal antibody in mice. Inhibition of cytotoxic $\mathrm{T}$ cell responses but not of $\mathrm{T}$ help. J. Immunol. 143:628-632.

4. Soulillou, J.P., et al. 1990. Randomized controlled trial of a monoclonal antibody against the interleukin-2 receptor (33B3.1) as compared with rabbit antithymocyte globulin for prophylaxis against rejection of renal allografts. N. Engl. J. Med. 322:1175-1182.

5. Waldmann, T.A. 1993 . The IL-2/IL-2 receptor system: a target for rational immune intervention. Immunol. Today. 14:264-270.

6. Schweizer, E., Papachrysanthou, A., Faendrich, F., Deltz, E., and Schroeder, P. 1994. Immunosuppression in small bowel transplantation-treatment with a monoclonal IL-2 receptor antibody (NDS 61). Transplant Proc. 26:3142-3143.

7. Isobe, M., et al. 1997. Treatment of murine cardiac allograft by monoclonal antibodies to IL-2 receptor $\alpha$ chain and $\beta$ chain. Transplant Proc. 29:2301-2302.

8. Smith, K.A. 1989. The interleukin 2 receptor. Annu. Rev. Cell Biol. 5:397-425.

9. Minami, Y., Kono, T., Miyazaki, T., and Taniguchi, T. 1993. The IL-2 receptor complex: its structure, function, and target genes. Annu. Rev. Immunol. 11:245-268.

10. Taniguchi, T., and Minami, Y. 1993. The IL-2/IL-2 receptor system: a current overview. Cell. 73:5-8.

11. Lohse, A.W., Mor, F., Karin, N., and Cohen, I.R. 1989. Control of experimental autoimmune encephalomyelitis by $\mathrm{T}$ cells responding to activated $\mathrm{T}$ cells. Science. 244:820-822.

12. Lohse, A.W., et al. 1993. Induction of the anti-ergotypic response. Int. Immunol. 5:533-539.

13. Mor, F., Reizis, B., Cohen, I.R., and Steinman, L. 1996. IL-2 and TNF receptors as targets of regulatory $\mathrm{T}-\mathrm{T}$ interactions: isolation and characterization of cytokine receptor-reactive $\mathrm{T}$ cell lines in the Lewis rat. J. Immunol. 157:4855-4861.

14. Hafler, D.A., Cohen, I., Benjamin, D.S., and Weiner, H.L. 1992. T cell vaccination in multiple sclerosis: a preliminary report. Clin. Immunol. Immunopathol. 62:307-313.

15. Zhang, J., Medaer, R., Stinissen, P., Hafler, D., and Raus, J. 1993. MHC-restricted depletion of human myelin basic protein-reactive $\mathrm{T}$ cells by $\mathrm{T}$ cell vaccination. Science. 261:1451-1454.

16. Cohen, I.R. 2001. T-cell vaccination for autoimmune disease: a panorama. Vaccine. 20:706-710.

17. Correale, J., Rojany, M., and Weiner, L.P. 1997. Human CD $8+\mathrm{TCR} \alpha / \beta^{+}$and TCR $\gamma / \delta^{+}$cells modulate autologous autoreactive neuroantigen-specific CD4+ T-cells by different mechanisms. J. Neuroimmunol. 80:47-64.

18. Stinissen, P., Zhang, J., Vandevyver, C., Hermans, G., and Raus, J. 1998. $\gamma / \delta$ T cell responses to activated T cells in multiple sclerosis patients induced by $\mathrm{T}$ cell vaccination. J. Neuroimmunol. 87:94-104.

19. Wauben, M.H.M., Wagenaar-Hilbers, J.P.A., and vanEden, W. 1994. Adjuvant arthritis. In Autoimmune disease models: a guidebook. I.R. Cohen and A. Miller, editors. Academic Press Inc. San Diego, California, USA. 201-216.

20. Wolff, J.A., et al. 1990. Direct gene transfer into mouse muscle in vivo. Science. 247:1465-1468.

21. Danko, I., et al. 1994. Pharmacological enhancement of in vivo foreign gene expression in muscle. Gene Ther. 1:114-121.

22. Pisetsky, D.S. 1996. Immune activation by bacterial DNA: a new genetic code. Immunity. 5:303-310.

23. Sato, Y., et al. 1996. Immunostimulatory DNA sequences necessary for effective intradermal gene immunization. Science. 273:352-354.

24. Gurunathan, S., Klinman, D.M., and Seder, R.A 2000. DNA vaccines: immunology, application, and optimization. Annu. Rev. Immunol. 18:927-974.

25. Hoffman, S.L., et al. 1997. Toward clinical trials of DNA vaccines against malaria. Immunol. Cell Biol. 75:376-381.

26. Wang, R., et al. 1998. Induction of antigen-specific cytotoxic $\mathrm{T}$ lymphocytes in humans by a malaria DNA vaccine. Science. 282:476-480.

27. Ugen, K.E., et al. 1998. DNA vaccination with HIV-1 expressing constructs elicits immune responses in humans. Vaccine. 16:1818-1821.

28. Le, T.P., et al. 2000. Safety, tolerability and humoral immune responses after intramuscular administration of a malaria DNA vaccine to healthy adult volunteers. Vaccine. 18:1893-1901.

29. Wang, R., et al. 2001. Induction of CD4(+) T celldependent $\mathrm{CD} 8(+)$ type 1 responses in humans by a malaria DNA vaccine. Proc. Natl. Acad. Sci. U. S. A. 98:10817-10822.

30. Mor, F., Kantorowitz, M., and Cohen, I.R. 1996. The dominant and the cryptic $T$ cell repertoire to myelin basic protein in the Lewis rat. J. Neurosci. Res. 45:670-679

31. Holoshitz, J., Matitiau, A., and Cohen, I.R. 1984 Arthritis induced in rats by cloned $\mathrm{T}$ lymphocytes responsive to mycobacteria but not to collagen type II. J. Clin. Invest. 73:211-215.

32. van Eden, W., et al. 1988. Cloning of the mycobacterial epitope recognized by $\mathrm{T}$ lymphocytes in adjuvant arthritis. Nature. 331:171-173.

33. Gillis, S., Ferm, M.M., Ou, W., and Smith, K.A. 1978. $\mathrm{T}$ cell growth factor: parameters of production and a quantitative microassay for activity. J. Immunol. 120:2027-2032.

34. Jiang, H., and Chess, L. 2000. The specific regulation of immune responses by CD8+ T cells restricted by the MHC class Ib molecule, Qa-1. Annu. Rev. Immunol. 18:185-216.

35. Sakaguchi, S. 2000. Regulatory T cells: key controllers of immunologic self-tolerance. Cell. 101:455-458.

36. Roncarolo, M.G., and Levings, M.K. 2000. The role of different subsets of $\mathrm{T}$ regulatory cells in controlling autoimmunity. Curr. Opin. Immunol. 12:676-683.

37. Shevach, E.M. 2000. Regulatory T cells in autoimmunity. Annu. Rev. Immunol. 18:423-449.

38. Roncarolo, M.G., Bacchetta, R., Bordignon, C., Narula, S., and Levings, M.K. 2001. Type 1 T regulatory cells. Immunol. Rev. 182:68-79.

39. Shevach, E.M. 2002. CD4+ CD25+ suppressor T cells: more questions than answers. Nat. Rev. Immunol. 2:389-400.

40. Quintana, F.J., Carmi, P., Mor, F., and Cohen, I.R 2002. Inhibition of adjuvant arthritis by a DNA vaccine encoding human HSP60. J. Immunol. 169:3422-3428

41. Ragno, S., et al. 1997. Protection of rats from adjuvant arthritis by immunization with naked DNA encoding for mycobacterial heat shock protein 65 Arthritis Rheum. 40:277-283.

42. Anderton, S.M., van der Zee, R., Noordzij, A., and van Eden, W. 1994. Differential mycobacterial 65-kDa heat shock protein $\mathrm{T}$ cell epitope recognition after adjuvant arthritis-inducing or protective immunization protocols. J. Immunol. 152:3656-3664.

43. Lopez-Guerrero, J.A., et al. 1993. Modulation of adjuvant arthritis in Lewis rats by recombinant vaccinia virus expressing the human 60-kilodalton heat shock protein. Infect. Immun. 61:4225-4231.

44. Lopez-Guerrero, J.A., Ortiz, M.A., Paez, E., Bernabeu, C., and Lopez-Bote, J.P. 1994. Therapeutic effect of recombinant vaccinia virus expressing the $60-\mathrm{kd}$ heat-shock protein on adjuvant arthritis. Arthritis Rheum. 37:1462-1467.

45. Boccaccio, G.L., Mor, F., and Steinman, L. 1999. Non-coding plasmid DNA induces IFN- $\gamma$ in vivo and suppresses autoimmune encephalomyelitis. Int Immunol. 11:289-296.

46. Quintana, F.J., Rotem, A., Carmi, P., and Cohen, I.R. 2000. Vaccination with empty plasmid DNA or $\mathrm{CpG}$ oligonucleotide inhibits diabetes in nonobese diabetic mice: modulation of spontaneous $60-\mathrm{kDa}$ heat shock protein autoimmunity. J. Immunol. 165:6148-6155.

47. Rachmilewitz, D., et al. 2002. Immunostimulatory DNA ameliorates experimental and spontaneous murine colitis. Gastroenterology. 122:1428-1441.

48. Groux, H., et al. 1997. A CD4+ T-cell subset inhibits antigen-specific T-cell responses and prevents colitis. Nature. 389:737-742.

49. Cottrez, F., Hurst, S.D., Coffman, R.L., and Groux, H. 2000. T regulatory cells 1 inhibit a Th2-specific response in vivo. J. Immunol. 165:4848-4853.

50. Kumar, V., et al. 2001. Induction of a type 1 regulatory CD4 $\mathrm{T}$ cell response following $\mathrm{V}$ beta 8.2 DNA vaccination results in immune deviation and protection from experimental autoimmune encephalomyelitis. Int. Immunol. 13:835-841.

51. Hayday, A.C. $2000 . \gamma / \delta$ cells: a right time and a right place for a conserved third way of protection. Annu. Rev. Immunol. 18:975-1026.

52. Harrison, L.C., Dempsey-Collier, M., Kramer, D.R., and Takahashi, K. 1996. Aerosol insulin induces regulatory CD8 $\gamma / \delta$ T cells that prevent murine insulindependent diabetes. J. Exp. Med. 184:2167-2174.

53. Peng, S.L., Madaio, M.P., Hayday, A.C., and Craft, J. 1996. Propagation and regulation of systemic autoimmunity by $\gamma / \delta \mathrm{T}$ cells. J. Immunol. 157:5689-5698.

54. Zang, Y.C., et al. 2000. Th2 immune regulation induced by $T$ cell vaccination in patients with multiple sclerosis. Eur. J. Immunol. 30:908-913.

55. Thornton, A.M., and Shevach, E.M. 1998 CD4+CD25+ immunoregulatory $\mathrm{T}$ cells suppress polyclonal $\mathrm{T}$ cell activation in vitro by inhibiting interleukin 2 production. J. Exp. Med. 188:287-296. 